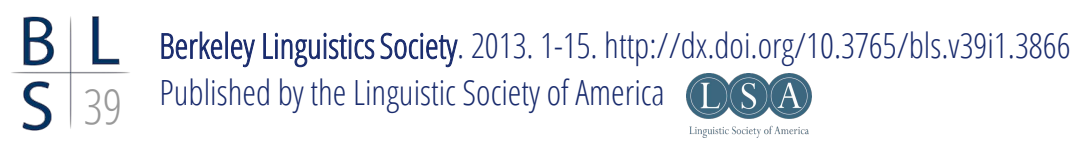

\title{
The Definite Marker in Arabic: Morphological realization of the syntactic head D or a [DEF] feature*
}

\author{
AHMAD ALQASSAS \\ Indiana University, Bloomington
}

\section{$1 \quad$ Introduction}

In Arabic, the definite marker can render a noun phrase (NP) definite and it appears as a proclitic on adjectives that modify a definite NP (a phenomenon known as definiteness agreement). Arabic also has a complex adjectival construction known as Construct State Adjective (CSA) that also exhibits the definiteness agreement property. Moreover, in cardinal number constructions in Standard Arabic, the definite marker appears as a proclitic on both the numeral and the enumerated noun (another case for definiteness agreement). This CSA construction and cardinal number constructions are interesting in that definiteness agreement is optional as opposed to the canonical cases of noun-adjective constructions (with post nominal adjectives) where definiteness agreement is obligatory. This paper argues that, given these facts about definiteness agreement, it is more plausible to treat the definite marker whish appears on nominal heads as the realization of the syntactic D head while the definite marker appearing on adjectival and nominal complements as a [DEF] feature added at PF. This analysis extends and builds on Kramer's (2010) analysis of definiteness in Amharic. In this section, I introduce the basic analyses of these facts. Then in section two, I review the approaches that have been entertained to explain the

\footnotetext{
* I would like to thank the audience of BLS 39 for their helpful comments on the earlier version of this paper presented during the conference. Thanks are also due to Steven Franks and Yoshi Kitagawa for their helpful comments on earlier versions of this paper.
} 
realization of the definite markers. In section three, I argue in favor of Kramer's analysis for analyzing the realization of the definite marker in Arabic and build on it by adding a $[\mathrm{DEF}]$ deletion process that can explain the complex patterns for the distribution of the definite marker in the Arabic noun phrase. And in section 4 I conclude.

The standard analysis of the Semitic DP (e.g., Fassi Fehri 1993) has the determiner located at its left periphery which selects an NP complement (Abney's 1987 analysis). The determiner, however, generally shows up as a prefix on the head of the NP. The determiner and the head of the NP are one prosodic word. When the determiner shows up as a prefix on a noun that has a coronal sound word initially, the lateral sound in the determiner [?al] assimilates to the coronal sound as in [Pa $\left.\int-\int a m s\right]$ 'the sun'. This word level phonological process has been explain by N-D movement suggesting that the word formation process that merges the determiner with the head of the NP is syntactic incorporation, i.e. the noun moves to the head of the DP and incorporates with the determiner (Benmamoun (1992, 2000b), Fassi-Fehri (1989, 1993, 1999), Mohammad (1988), Ouhalla (1991)). The trees in examples (1) illustrate this.

(1) a.

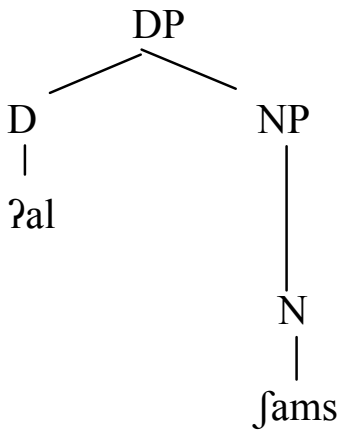

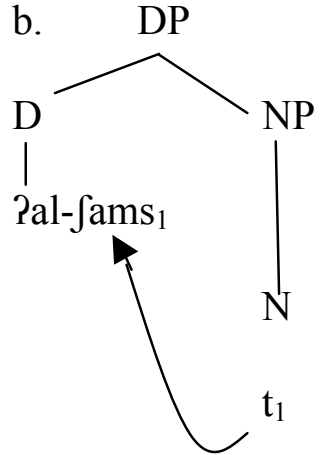

Shlonsky (2004) criticizes this incorporation analysis. He points out that incorporating the noun with the determiner should result in the wrong word order, i.e. the noun will left adjoin to the determiner since incorporation is left adjunction. Therefore, we need to introduce another mechanism into the syntax in order to get the right word order under the incorporation analysis. This extra mechanism is to allow heads to right adjoin in incorporation. Following the spirit of the minimalist program, Shlonsky argues against incorporation to explain the merger between the determiner and the head noun of the NP. Instead, he adopts Siloni's (2001) postsyntactic analysis of this phenomenon. Siloni proposes that the determiner merges with the noun after spell out at the PF side by prosodic licensing. Specifically, Siloni argues that the determiner merges with the noun at the prosodic level when prosodic structure is built. She proposes that prosodically weak words are function words that attach to prosodic words. The determiner attaches to the noun because it is prosodically weak. Siloni basically proposes this 


\section{The Definite Marker in Arabic}

to explain why the determiner cannot show up on the construct state heads in Hebrew.

Some adjectives precede the head of the DP and others follow it. The prenominal adjectives have been analyzed as heads in an AP that dominates the DP. The heads assign genitive case to the NP (Shlonsky 2004), as in (2) and the illustration in (3).

(2) jamiilat-u al-wajh-i

beautiful-NOM the-face-GEN

'beautiful of face'

(3)

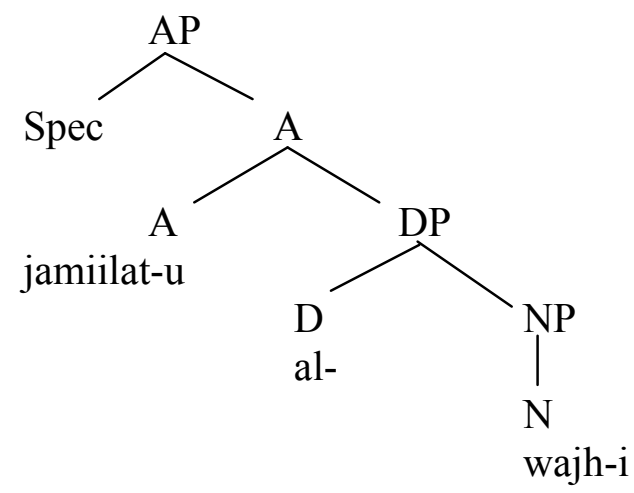

The post-nominal adjectives have been analyzed as specifiers in Spec-NP and the head of the NP moves higher to a NumP and incorporates with Num ${ }^{0}$. In the possessive/genitive construction (Construct State Nominal (CSN)) ${ }^{1}$ as in e.g. (4) below, on the contrary, the head noun has been argued to move to the head of the DP because the determiner never appears as a prefix on the head of the NP as in e.g. (4) below where the CSN head noun kitaab-u 'book-NOM' cannot carry the determiner. The complementary distribution between the determiner and the head of the genitive construction has been viewed as a competition between these two heads illustrated in e.g. (4) to occupy the same head position of the DP (Ritter 1991, Fassi-Fehri 1993, Borer 1996 and others). Accordingly, Construct State Nominal (CSN) is often analyzed as follows. First, a head noun is merged with a DP and assigns genitive case to this DP. In (4) below, for example, the head noun kitaab-u 'book-NOM' first merges with the genitive DP2 al-bint- $i$ 'the-girl-GEN' at the bottom of the tree in (5).

\footnotetext{
${ }^{1}$ The term construct state refers to the weak state of the head of the genitive construction. The head is morphologically weak in Modern Standard Arabic and phonologically weak/reduced in Hebrew and some Arabic dialects. Morphologically, the head lacks the morpheme $-n$ when it is indefinite. Indefinite nouns have this $-\mathrm{n}$ suffix but not when they are used as heads of the genitive construction.
} 
Ahmad Alqassas
(*al-)kitaab-u
al-bint-i
*(al-)kabiir-u
(*the)book-NOM
the-girl-GEN
the-large-NOM
'the big book of the girl'

$(5)$

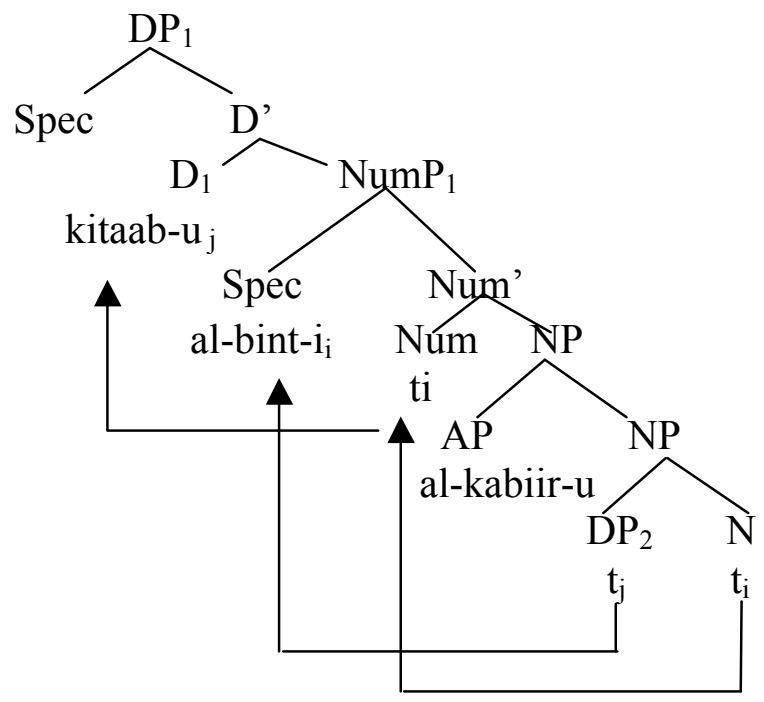

The NP which is composed of the noun kitaab- $u$ and the genitive DP2 then merges with the adjective al-kabiir- $u$ 'the-large-nom' which modifies the head noun kitaab-u. The head noun kitaab-u then moves to NumP to pick up the number morpheme. The genitive DP2 moves to Spec NumP to check its gentitve case and the head noun kitaab- $u$ inherits definiteness from the definite DP2 in turn. The head kitaab-u then moves to the D1 head of the highest DP and turns the whole possessive construction into a definite DP. Although the head kitaab-u morphologically lacks the definite article, it is claimed to be definite because it is ungrammatical to delete the definite article which appears on the adjective alkabiir. Adjectives must carry the article whenever the noun they modify is definite. This is known as definiteness concord in Semitic. The adjective also shows agreement in phi features with the noun it modifies.

In addition to CSN, there is another 'Construct State (CS)' construction generally referred to as Construct State Adjective (CSA). ${ }^{2}$ This construction involves an adjectival head that merges with a DP and assigns genitive case to this DP ('the internal DP'), as in the examples from Modern Standard Arabic (MSA) in (6). In example (6), the adjective and its internal DP function as an attributive modifier for the $\mathrm{N}$ in a higher DP ('the external DP'). The adjective head agrees with the noun in the external DP in $p h i$ features. CSA does not have a definite interpretation and it is used as an attributive modifier for the noun in the external DP. It is the adjective that shows concord and the internal DP always

\footnotetext{
${ }^{2}$ Although adjectives agree with the nouns they modify in definiteness, the adjective in CSA lacks the indefinite morpheme $-\mathrm{n}$. This is similar to what happens to the head noun in CSN.
} 


\section{The Definite Marker in Arabic}

carries the definite article regardless of the definiteness value of the external DP, as in (6).

(6) a. [DP bint-un [AP[A $(* a l-) j a m i l a t-u] \quad[D P *(a l-) w a j h-i]]]$ girl(FS)-NOM (*the-)beautiful(3FS)-NOM *(the-)look(MS)-GEN 'A good looking girl'

b. [DP al-bint-u [AAP[A $*($ al- $)$ jamilat-u $]$ [DP *(al-)wajh-i $]]$ the-girl(FS)-NOM *(the-)beautiful(3FS)-NOM *(the-)look(MS)- GEN 'The good looking girl'

The following tree in (7) represents the CSA in example (6):

(7)

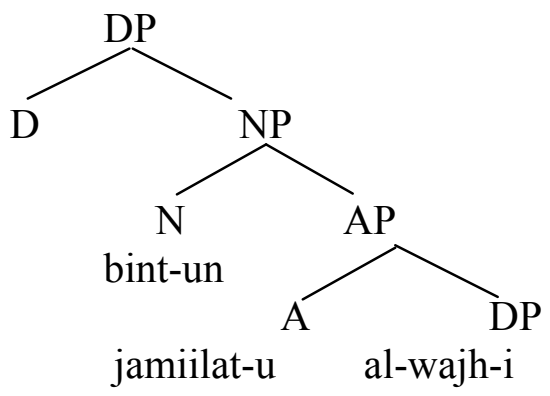

\section{Theoretical Background and Previous Analyses}

Under the DP hypothesis (Abney 1987), the definite article is assumed to be basegenerated under the syntactic head D (Ouhalla 2004). A second approach treats it as a morphosyntactic feature $[\mathrm{DEF}]$ generated on the lexical host (noun or adjective) through a definiteness agreement with (abstract) D (Fassi Fehri 1999; Shlonsky 2004; den Dikken 2007). The first is problematic in languages that exhibit definiteness agreement on adjectives like Arabic (e.g. (8)). There is no explanation for how the adjective can carry the definite marker since the AP does not have a D head. Moreover, this agreement process is sometimes optional as in Amharic multiple adjectives (e.g. (9)). The second approach is also problematic in cases of multiple instances of the definite marker (e.g. (9)). An extra mechanism like (multiple Agree) is needed and even with this it is not possible to explain the optionality of agreement. It is also not possible to explain the absence of the marker from nouns modified by adjectives in Amharic since the presence of the marker is expected, given that the noun is specified for [DEF]. The third approach is a hybrid analysis (Kramer 2010) for the Amharic DP where the determiner of the noun phrase is the realization of the $\mathrm{D}$ head (which has a [DEF] feature) which undergoes local dislocation at $\mathrm{PF}$, while the definiteness agreement marker carried by the adjective is the realization of a $[\mathrm{DEF}]$ feature added at PF (a distributed morphology analysis). 
(8) [DP al-bint-u [AP [A *(al-)jamil-at-u ]

DEF-girl-NOM *(DEF-)beautiful-FS -NOM

'The beautiful girl'

(9) tillik'-u t'ik'ur(-u) bet

big-DEF black(-DEF) house

'the big black house'

For Arabic, the second approach has been assumed. The definite marker has been considered as the realization of [DEF] features on nouns and adjectives (Shlonsky 2004, Fassi Fehri 1999). The noun, which has a [DEF] feature, enters into a Spec-Head relationship to license the $[\mathrm{uDEF}]$ feature of the adjective (as well as the phi features). This movement explains how adjectives are postnominal. Further movement of the noun to D (head-to-head movement $=$ incorporation) to render the whole DP definite and this explains the fact that the definite marker is a clitic. However, there are at least 4 reasons that make this analysis disfavored. First, Arabic allows multiple instances of the definite marker (e.g. (8)) and this requires multiple Agree. Second, cardinal number constructions in Standard Arabic have optional definiteness agreement on the enumerated noun (e.g. (10), (11) and (12)). Moreover, a certain type of adjectives (construct state adjectives $=$ CSA) in Jordanian Arabic allows optional definiteness agreement on these adjective (e.g. (13) and (14)). The optionality cannot be explained under the second approach. Third, the internal noun 'baal' in (4b) cannot enter into an Agree process to value its $[\mathrm{uDEF}]$ feature since this noun is not in a c-command relation with the external noun 'el-zalam' with which is agrees. This problem can only be solved by introducing an extra mechanism like 'feature sharing' as in Danon (2008). Fourth, the outcome of incorporating the noun with the syntactic head $\mathrm{D}$ creates the wrong word order $\left[\mathrm{N}^{*} \mathrm{D}\right]$ since heads left-adjoin to heads they incorporate with.

(10) al-xamsat-u Pawlaad-i

DEF-five-NOM boys-GeN

'the five boys'

(11) al-xamsat-u

al-Pawlaad-i

DEF-five-NOM

DEF-boys-GEN

'the five boys'

(12) xamsat-u al-Pawlaad-i

five-NOM DEF-boys-GeN

'the five boys' 
(13) [DP el-zalam [AP [A el-tawiil [NP baal]]]] DEF-Man-NOM DEF-long patience 'the patient man'

(14) ? [DP el-zalam [AP [A tawiil [NP el-baal]]]] DEF-man-NOM long DEF-patience 'the patient man'

(15) [DP el-zalam [AP [A el-tawiil [NP el-baal]]]] DEF-man-NOM DEF-long DEF-patience 'the patient man'

I argue in favor of the third approach. I propose a post-syntactic Agr-Insertion rule that is obligatory for adjectival modifiers, and this explains the presence of the definite marker in examples (8) and (15) on the adjectives 'beautiful' and 'long' respectively. But this Agr-Insertion rule is optional for nominal complements, and this explains how the nominal complements 'boys' and 'patience' carry the definite marker optionally (see contrast between (10) and (11) and between (13) and (15)). I also propose an 'impoverishment' process that optionally deletes the $[\mathrm{DEF}]$ feature of the adjectival and nominal head that assigns genitive case to its complement. These heads are the numeral 'five' and the adjective 'long' in examples (12) and (14). This process applies at PF. I show that this explains all the facts of definiteness marking in the CSA and cardinal number constructions in the Arabic examples above. I show that this analysis can avoid the 3 problems mentioned above. We avoid the extra mechanism called feature sharing Agree proposed by Danon (2008) to explain the CSA internal noun valuation of its $[\mathrm{uDEF}]$. We also eliminate optionality of definiteness agreement in CSA and Cardinal number phrases from syntax and move it to PF since optionality is not desirable in the minimalist program. Moreover, it avoids the presence of uninterpretable features in syntax. This simplifies the syntax proper since there is no need to value these features and no need to delete/erase them. Finally, it accounts for the fact that the article is a proclitic without the need to stipulate right incorporation. In my analysis the definite marker simply locally dislocates with the noun at PF in the sense of Embick and Noyer (2001).

\section{Proposal: third approach for Arabic}

I propose a Distributed Morphology analysis for the realization of the definite marker in Arabic. The definite marker is the realization of the syntactic D head when it appears on NP/CardP heads. But it is a dissociated morpheme inserted at PF (post-syntactic) when it appears on adjectival modifiers (AP heads). Marantz (1992), Halle \& Marantz (1993) and Halle (1997) analyze subject-verb agreement in terms of the post-syntactic adjunction of an [Agr] morpheme to T (cf. Embick 


\begin{abstract}
Ahmad Alqassas
(1997) for a detailed discussion of the insertion of dissociated morphemes, and cf. Fuß (2004) for an analysis of complementizer agreement in Germanic in terms of dissociated [Agr] morphemes). Kramer (2010) develops an analysis of definiteness agreement in Amharic as a dissociated Agr-morpheme. (16) shows the order of operations on the PF branch (articulated by Embick and Noyer 2001):
\end{abstract}

(16) Order of operations on the PF branch.

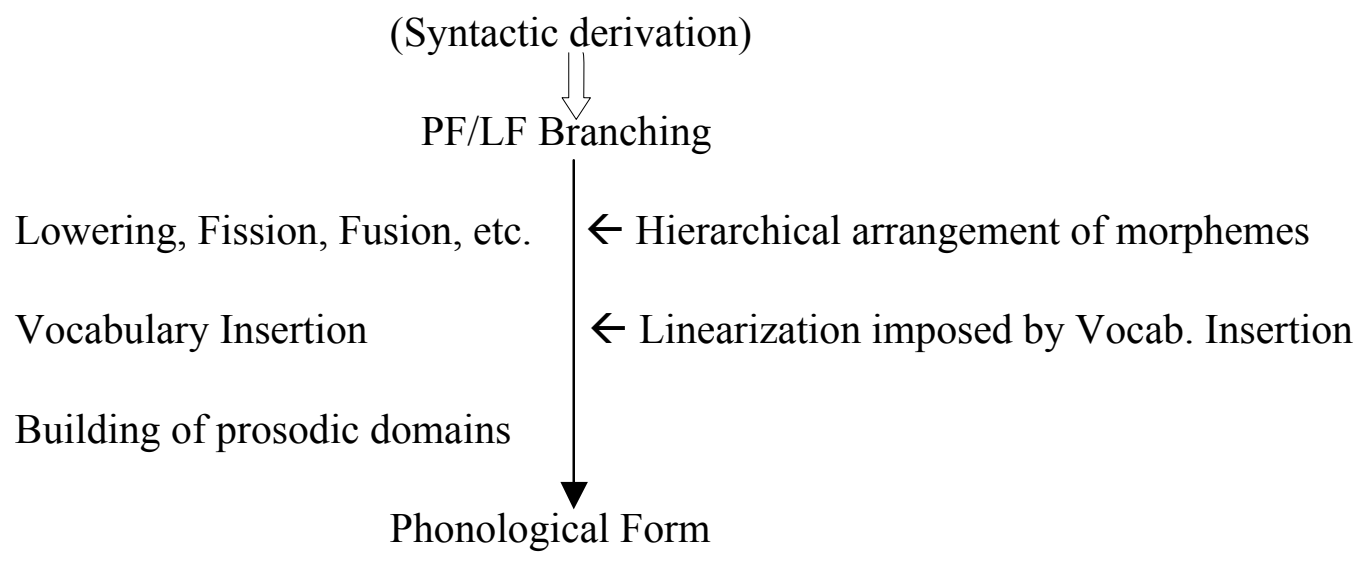

I propose a post-syntactic Agr-Insertion rule (as in (17)) that is obligatory for adjectival modifiers, and this explains the presence of the definite marker on adjectival modifiers whether single word adjectives (e.g.(19)) or adjectives that take nominal complements (e.g.(20)). This is also consistent with the norm for adjectival modifiers to have agreement in definiteness and phi features. This AgrInsertion takes place at PF and a dissociated Agr node is inserted to the left of the A node. The $[\mathrm{DEF}]$ feature of the closest c-commanding $\mathrm{D}$ head is then copied into the Agr node, as in (18) which is illustrated by the trees in example (21).

(17) Agr-Insertion (Obligatory)

$$
\mathrm{A} \longrightarrow[\mathrm{A} \mathrm{Agr}]
$$

(18) Feature Copying

The $[\mathrm{DEF}]$ feature on the closest c-commanding D is copied into the Agr node attached to $\mathrm{A}$.

(19) [DP al-bint-u [AP [A *(al-)jamil-at-u ] DEF-girl-NOM *(DEF-) beautiful-FS -NOM 'the beautiful girl'

(20) [DP el-zalam [AP [A el-tawiil [NP baal]]]] DEF-man-NOM DEF-long patience 'the patient man' 
(21)

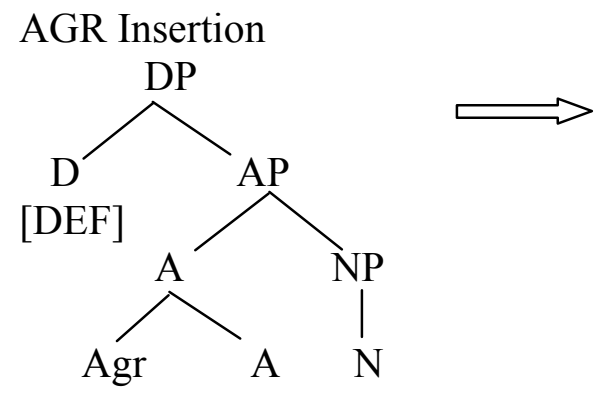

b. Feature Copying:

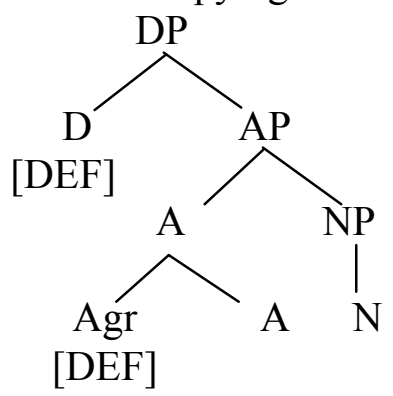

But the Agr-Insertion rule is optional (as in (22)) for nominal complements agreeing with their heads. As with the previous example, the [DEF] feature of the closest c-commanding head is copied into the Agr-node. But here it is that ccommanding head is the D in example (24) and the A in example (25). This explains how in examples (24) and (25) the nominal complements 'boys' and 'patience' carry the definite marker optionally. Example (26) illustrates the optionality of DEF in Nominal complements of numeral phrases, and example (27) shows the optionality of DEF in nominal complements of CSA.

Agr-Insertion (Optional)

$\mathrm{N} \longrightarrow[\mathrm{N}$ Agr]

(23) Feature Copying

The $[\mathrm{DEF}]$ feature on the closest c-commanding $\mathrm{D} / \mathrm{A}$ is copied into the Agr node attached to $\mathrm{N}$.

$$
\begin{array}{ll}
\begin{array}{l}
\text { al- xamsat-u } \\
\text { DEF-five-NOM }
\end{array} & \text { (al)-Pawlaad-i } \\
\text { 'the five boys' } & \text { (DEF)-boys-GEN }
\end{array}
$$

(25) [DP el-zalam [AP [A el-tawiil [NP (el)-baal] $]]$

DEF-man-NOM DEF-long (DEF)-patience

'the patient man' 
Ahmad Alqassas
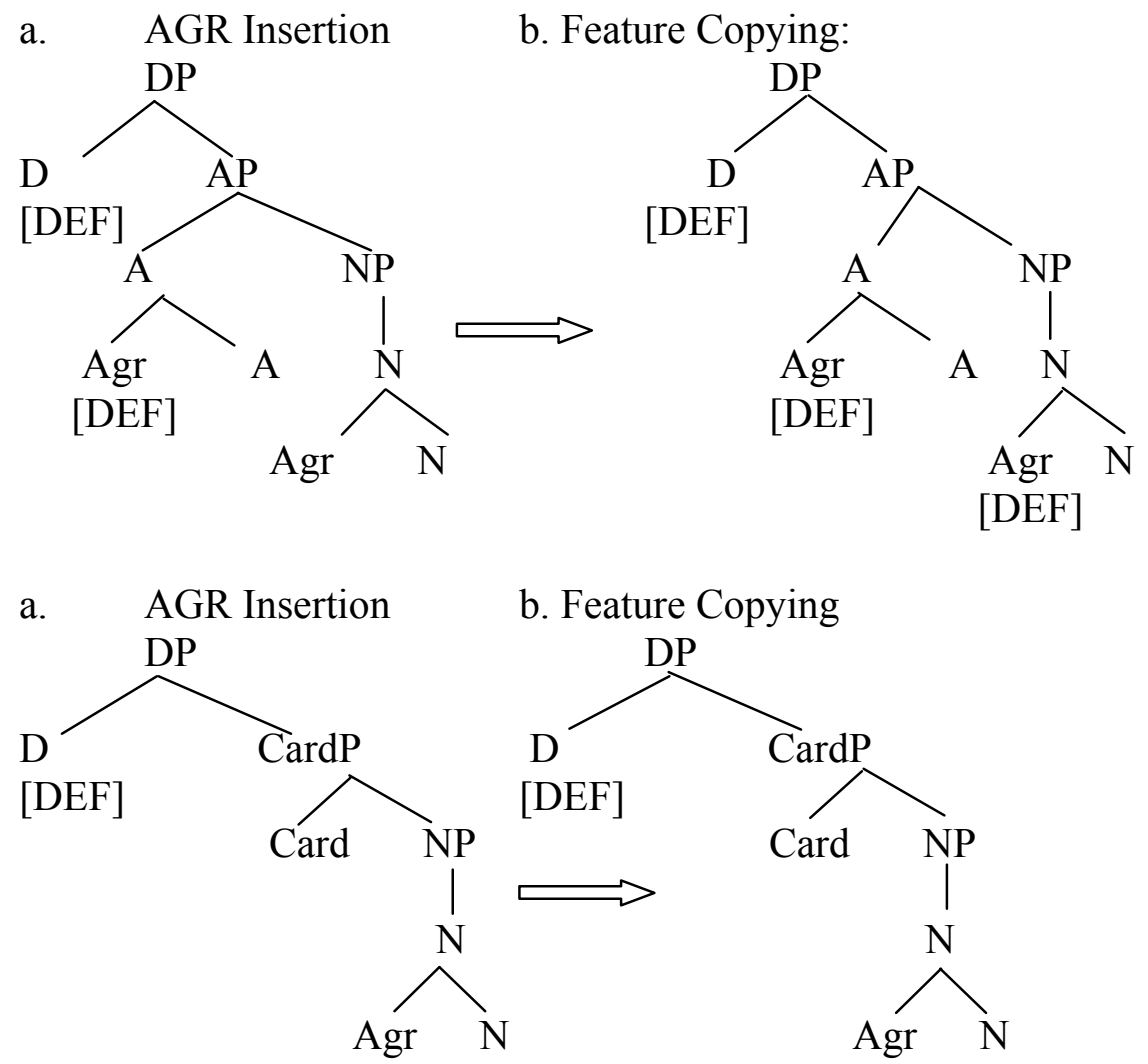

b. Feature Copying

Agr N
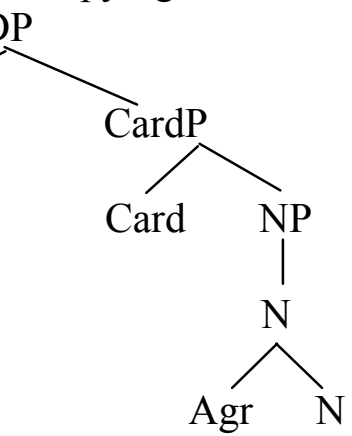

$[\mathrm{DEF}]$

Now for (12) and (14) where the [DEF] of the heads D and A is absent, I propose an impoverishment process in the Distributed Morphology (DM)sense. In DM, impoverishment involves the deletion of certain morphosytactic features from morphemes in certain morphological environments (See Embick 2007 on impoverishment in Standard Arabic case system). This deletion process applies at PF and guarantees blocking of Vocabulary Insertion for the deleted morphemes. This process optionally deletes the $[\mathrm{DEF}]$ feature of the syntactic head that assigns genitive case to its nominal complement. These heads are the numeral 'five' and the adjective 'long' in examples (12) and (14). So DEF deletion can be stated via an Impoverishment rule in (28):

(28) Impoverishment Rule

$\mathrm{DEF} \rightarrow \varnothing /$------ [adjective]+DEF+[noun]+gen.case

$\mathrm{DEF} \rightarrow \varnothing /$------ [cardinal] $+\mathrm{DEF}+[$ noun $]+$ gen.case

It is important to discuss one more CSA example that challenges my analysis and sheds more light on the complex distribution of the definite marker in this construction. Consider example (29) where the nominal complement el-baal optionally carries the definite marker despite the fact that the CSA construction has an indefinite interpretation. 


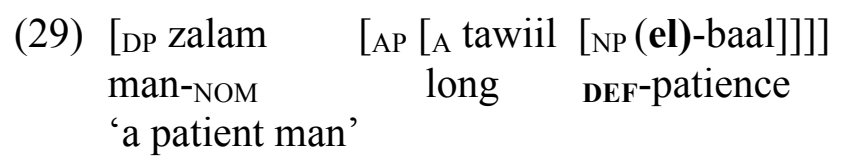

In this case, one might reasonably conclude that the definite marker carried by the same noun in example (14) is not an instance definiteness agreement. However, I would like to maintain that in example (14) the nominal complement carries $[\mathrm{DEF}]$ as an agreement morpheme, but in example (29) the nominal complement carries the generic marker as a marker for nouns which have generic reference. In other words, the marker in example (29) not the realization of a [DEF] feature, but it is merely a generic article homophonous with the definite marker. Consider example (30) where the complement of the verb is a noun that has generic reference and indeed the generic article is optional in Jordanian Arabic.

(30) Ali byudrus (al-)?adab

Ali studies (the-)literature

'Ali is studying literature'

Now if the analysis of the article in example (29) as a generic article (rather than an agreement article) is on the right track, one can make the prediction that this article cannot reflect the required definiteness agreement that post-nominal adjectives modifying a definite noun phrase exhibit. This prediction is borne out in Standard Arabic which does not allow the absence of the generic article from nouns which have a generic reference, as in example (31). Because the generic noun always carries the generic article in Standard Arabic, the CSA head has to carry the definite marker to show definiteness concord with the definite noun it modifies in example (32). In other words, the impoverishment process is blocked in example (32) because this example does not have the right environment for deleting the $[\mathrm{DEF}]$ morpheme of the CSA adjectival head.

(31) Ali yadrus *(al-) Padab

Ali studies *(the-)literature

'Ali is studying literature'

(32) $[\mathrm{DP}$ al-bint-u [AA [A *(al-)jamilat-u $] \quad[\mathrm{DP} *($ al- $)$ wajh-i $]]$ the-girl(FS)-NOM *(the-)beautiful(3FS) -NOM *(the-)look(MS)-GEN 'The good looking girl'

One might ask why the impoverishment process takes place. One possibility is analogical change. Analogy is a process whereby one form of a language becomes more like another with which it is somehow associated (Campbell \& Mixco 2007); Cardinal numbers (e.g., (33)) and adjectival heads of CSA (e.g., (34)) both select genitive nouns and check their genitive case. 
Ahmad Alqassas

(33) $[\mathrm{DP}$ bint-un $\quad[\mathrm{AP}[\mathrm{A}$ jamilat-u $] \quad[\mathrm{DP} *($ al- $)$ wajh-i $]]$

girl(FS)-NOM beautiful-NOM *(the-)look-GEN

'A good looking girl'

(34) al-xamsat-u (al)-Pawlaad-i

DEF-five-NOM (DEF)-boys-GEN

'the five boys'

Construct State heads also select genitive nouns, as in (35):

(35) (*al-)kitaab-u al-bint-i

(*the)book-NOM the-girl-GEN

'the book of the girl'

\section{Conclusion}

This paper shows that the realization of the definite marker in the Arabic complex noun phrase cannot be explained under the analyses which treat the definite marker as merely the realization of the syntactic head D (the general assumption under the DP-hypothesis) or as a [DEF] feature generated on lexical host through Definiteness Agreement (DA) with (abstract) D (Fassi Fehri 1999). This paper argues in favor of a hybrid analysis (Kramer 2010) where NP determiners realize a $[\mathrm{DEF}]$ marked $\mathrm{D}$ head, while DA markers for adjectives realize a [DEF] feature added at PF.

Extending and building on Kramer's 2010 analysis, I proposed a postsyntactic Agr-Insertion rule that is obligatory for adjectival modifiers but optional for nominal complements. I also proposed an 'impoverishment' process that optionally deletes the dissociated [DEF] feature of the case assigning heads at the PF linear level. This explains all the facts of definiteness marking in Construct State Adjectives (CSA) and Cardinal Number $(\mathrm{CN})$ constructions.

The analysis in this paper has the following advantages. First, we avoid the extra mechanism called feature sharing Agree proposed by Danon (2008) to explain the CSA internal noun valuation of its [uDEF]. Second, we also eliminate optionality of definiteness agreement in CSA and Cardinal number phrases from syntax and move it to PF since optionality is not desirable in the minimalist program. Third, it avoids the presence of uninterpretable features in syntax. This simplifies the syntax proper since there is no need to value these features and no need to delete/erase them. Fourth, it accounts for the fact that the article is a proclitic without the need to stipulate right incorporation. In my analysis the definite marker can simply locally dislocates with the noun at PF in the sense of Embick and Noyer (2001). 
The Definite Marker in Arabic

\section{References}

Abney, S. 1987. The English noun phrase in its sentential aspect. Ph.D. dissertation, MIT, Cambridge, MA.

Benmamoun, E. 1992. Functional and inflectional morphology: problems of projection, representation and derivation. Ph.D. dissertation, University of Southern California.

Benmamoun, E. 2000. The Feature Structure of Functional Categories. A Comparative Study of Arabic Dialects. Oxford University Press, Oxford, New York.

Borer, H. 1996. The construct in review. Lecarme, et al (1996: 30-61).

Borer, H. 1999. Deconstructing the construct. In: K. Johnson, I. Roberts, eds., Beyond Principles and Parameters. Kluwer, Dordrecht, pp. 43-89

Danon, G. 2008. Definiteness spreading in the Hebrew construct state. Lingua $118,872-906$.

den Dikken, M. 2007. Amharic relatives and possessives: Definiteness, agreement, and the linker. Linguistic Inquiry 38: 302-320.

Embick, D. \& R. Noyer. 2007. Distributed morphology and the syntax/morphology interface. In: G. Ramchand \& C. Reiss, eds., The Oxford handbook of linguistic interfaces, 289-324. Oxford: Oxford University Press.

Embick, D. and Noyer, R. 2001. "Movement Operations after Syntax", Linguistic Inquiry 32(4): 555-95.

Fassi-Fehri, A. 1989. Generalised IP structure, case and VS order. In: I. Laka, A. Mahajan, eds., Functional Heads and Clause Structure. MIT Working Papers in Linguistics, Department of Linguistics and Philosophy, Massachusetts Institute of Technology, Cambridge, MA, pp. 75-111.

Fassi-Fehri, A. 1993. Issues in the Structure of Arabic Clauses and Words. Kluwer, Dordrecht.

Fassi Fehri, A. 1999. Arabic modifying adjectives and DP structures. Studia Linguistica 53 (2), 105-154.

Fuß, E. 2004. Diachronic clues to pro-drop and complementizer agreement in Bavarian. In: E. Fuß and C. Trips, eds., Diachronic clues to synchronic grammar, 59-100. Amsterdam: Benjamins.

Halle, M. 1997. Distributed morphology: Impoverishment and fission. In: B. Bruening, Y. Kang and M. McGinnis, eds., MITWPL 30: Papers at the Interface. MITWPL, Cambridge, 425-449.

Halle, M. \& A. Marantz. 1993. Distributed morphology and the pieces of inflection. In: K. Hale \& S. J. Keyser, eds., The view from Building 20, 111176. Cambridge, MA: MIT Press.

Kramer, R. 2010. The Amharic Definite Marker and the Syntax-Morphology Interface. Syntax 13:3, 196-240. 


\section{Ahmad Alqassas}

Marantz, A. 1992. How morphemes are realized phonologically. Paper presented at the DIMACS Workshop on Human Language, Princeton University. Manuscript, MIT.

Mohammad, M.A. 1988. On the parallelism between IP and DP. Proceedings of the West Coast Conference on Formal Linguistics, vol. 7, pp. 241-254.

Ouhalla, J. 1991. Functional Categories and Parametric Variation. Routledge, London.

Ouhalla, J. 2004. Semitic relatives. Linguistic Inquiry 35: 288-300.

Ritter, E., 1991. Two functional categories in noun phrases: evidence from Modern Hebrew. Syntax and Semantics 25, 37-62.

Shlonsky, U. 2004. The form of Semitic noun phrases. Lingua 114 (12), 14651526.

Siloni, T. 2001. Construct states at the PF interface. In: P. Pica, J. Rooryck, eds., Linguistic Variation Yearbook, vol. 1. John Benjamins, Amsterdam, pp. 229266.

Siloni, T. 2002. Adjectival constructs and inalienable constructions. In J. Ouhalla and U. Shlonsky, eds., Themes in Arabic and Hebrew Syntax. Dordrecht, Holland: Kluwer.

Ahmad Alqassas

3209 E 10th St.

Apt. D24

Bloomington, IN 47408

aalqassa@imail.iu.edu 